\title{
EXPERIMENTOS DE LIXIVIAÇÃO DE METAIS EM CORPOS-DE-PROVA DE CIMENTO BRANCO RELACIONADDOS COM A POSSÍVEL CONTAMINACCÃO DO CIMENTO PRODUZIDO A PARTIR DA QUEIMA DE RESÍDUOS INDUSTRIAIS
}

\author{
Luciane Pimentel Costa Monteiro ${ }^{1}$ \\ Fernando Benedicto Mainier ${ }^{2}$
}

\begin{abstract}
Resumo - No passado, as plantas de cimento dependiam da queima de óleo combustível em suas indústrias para suprir suas necessidades energéticas. Após as décadas de 80/90, a redução dos combustíveis fósseis e o incentivo à utilização de combustíveis alternativos intensificaram a queima de resíduos orgânicos da agricultura (bagaço de cana, palha de arroz, galhos secos) desde que esses resíduos tivessem o poder calorífico aceitável, tais como os resíduos de outros segmentos industriais e pneus inservíveis. Contudo, a indústria cimenteira deve estar atenta de como tais resíduos, ao serem queimados, podem ser tóxicos ao ser humano e ao ambiente. Dependendo de sua origem, os riscos ambientais aumentam e podem comprometer a qualidade do cimento produzido. $\mathrm{O}$ estudo, com base em experimentos de lixiviação em laboratório, serve para alertar a sociedade dos riscos ambientais e humanos na presença desses contaminantes(compostos de metais pesados) durante a queima desses combustíveis alternativos em seus fornos de produção de clínquer.
\end{abstract}

Palavras-chave: chaves: cimento, combustíveis, lixiviação.

\begin{abstract}
In the past the cement plants depends on to burn combustible oil, mineral and/or vegetal coal to supply its energy necessities. After the $80 \mathrm{~s} / 90 \mathrm{~s}$ decades, the reduction of fossils fuels and the incentive to the alternative fuel use, intensified the use of agriculture organic residues (sugar cane pulp, rice straw, wood waste) since those residues have the calorific heat acceptable such as others residues from some industrial segments and used tires. However, this industry must be alert how much the residues burning are toxic, contaminating the ambient and the human. Depending on the origin of the alternative fuel, the ambient risks increase and also they compromise the quality of the produced cement. The study on the basis of laboratory assays aims to alert the society of the ambient and human risks related to the presence of contaminants (heavy metals compounds) during the alternative fuel burning in its ovens of production of clinker.
\end{abstract}

Keywords: cement, fuels, leading.

\section{INTRODUÇÃO}

Com o objetivo de reduzir os custos de produção relacionados à energia, a indústria cimenteira ampliou sua disposição para incinerar resíduos industriais nos fornos rotativos de clínquer de cimento, substituindo parte dos combustíveis convencionais por diversos tipos de resíduos gerados em outras unidades industriais. Essa possibilidade de substituição energética tem se desenvolvido nos últimos anos, tendo em vista, entre outros aspectos, a preparação de blends compostos por misturas de diferentes tipos de resíduos, visando a uma maior eficiência energética. Em alguns ca-

Departamento de engenharia Química e Petróleo, TEQ- lucianemonteiro@predialnet.com.br

2 Departamento de Engenharia Química e Petróleo, TEQ - mainier@nitnet.com.br 
sos, o resíduo é processado com a finalidade única de substituição dos componentes inorgânicos da farinha crua, ou seja, da alumina, da sílica ou do óxido de ferro, não havendo geração de energia térmica (BRAGA, 2000).

No que diz respeito à carga térmica, esta é necessária de forma contínua e é de cerca de mil toneladas de combustível para queima nas plantas menores e, mais de cinco mil toneladas, nas plantas de maior porte. Para o processamento de 3.600 toneladas de clínquer, principal componente do cimento, em um único forno por dia, é necessário um forno rotativo de maior capacidade que, consumindo somente óleo combustível, consumirá cerca de 300 toneladas desse energético, ou seja, dez caminhóes-tanque.

No Brasil, o número de plantas cimenteiras instaladas é constituído por 47 fábricas de clínquer consumindo o equivalente a 39,48\% do consumo final de energéticos no país (SANTI \& SEVÁ,1999).

Por volta dos anos 1979-1981, o óleo combustível teve seu preço triplicado por causa da dependência nacional criada do petróleo importado. Houve, então, a criação de cotas para fornecimento de óleo combustível às indústrias, não devendo ultrapassar os consumos praticados em 1979 (LEMARCHAND, 1999). Assim, foram criados os incentivos e subsídios a algumas fontes alternativas de combustíveis e energia térmica, através da assinatura de protocolos para a utilização do carvão mineral nacional pelas indústrias de aço, cimento e papel e celulose (SANTI \& SEVÁ,1999).

Em setembro de 1979, as indústrias de cimento assinaram o "Protocolo de Redução e Substituição do Consumo de Óleo Combustível na Indústria Cimenteira", onde, se comprometeram a atingir no final de 1984, a substituição total do óleo combustível consumido em suas plantas pelo carvão mineral nacional e, adotar medidas de conservação de energia no nível da fábrica. Desse modo, no ano de 1985, a indústria cimenteira já havia substituído cerca de 95\% do valor do óleo combustível antes consumido (SANTI E SEVÁ, 1999).

\section{CIMENTO PRODUZIDO A PARTIR DA QUEIMA DE RESÍDUOS INDUSTRIAIS}

O cimento mais comumente utilizado é composto de $96 \%$ de clínquer e $4 \%$ de gesso em massa, em sua composição. O clínquer é produzido a partir da transformação térmica em fornos giratórios a elevadas temperaturas, de um material rochoso contendo, normalmente, $80 \%$ de carbonato de cálcio $\left(\mathrm{CaCO}_{3}\right), 15 \%$ de dióxido de silício $\left(\mathrm{SiO}_{2}\right), 3 \%$ de óxido de alumínio $\left(\mathrm{Al}_{2} \mathrm{O}_{3}\right)$ $\mathrm{e}$, quantidades menores de outros constituintes como o ferro, o enxofre e outros. Esses materiais são encontrados em jazidas de calcário, localizadas nas proximidades dos fornos de produção de clínquer. A matéria-prima é misturada e moída finamente, sendo submetida a um processo de aquecimento que leva à produção final do clínquer (BATTAGIN,2003).

A energia necessária à secagem, calcinação e sinterização do clínquer é obtida pela queima de uma variedade de combustíveis, dos quais os mais comumente empregados são o carvão mineral, gás natural e óleo combustível (BATTAGIN, 2003).

Segundo Cavalcanti (1998), são utilizados combustíveis alternativos como pneus usados, papel velho, resíduos de madeira, resíduos de indústrias de fármacos, petróleo, petroquímica, e outros, em período anterior à década de 70 , porém, esse fato, atualmente, não se modificou, entretanto, nem sempre as normas são atendidas para este fim. A Fig. 1, a seguir, apresenta o esquema de um forno típico de incineração de resíduos.

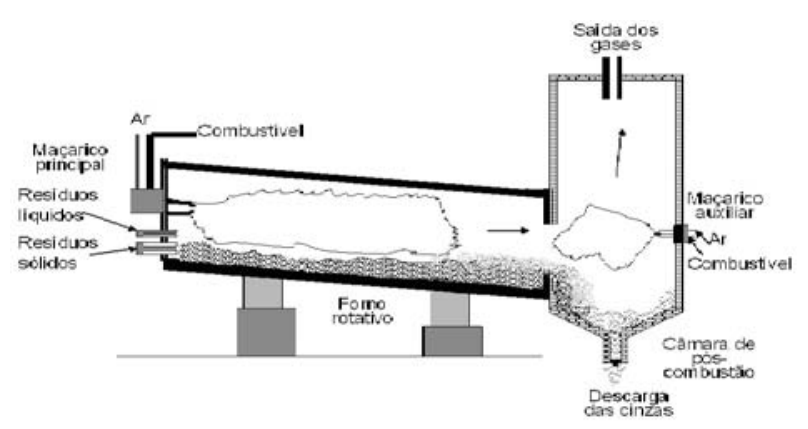

Fig 1: Esquema típico de forno rotativo para queima de resíduos

Ao se utilizar esses resíduos, além dos elementos maiores cálcio, silício, ferro e alumínio, outros elementos são introduzidos com os combustíveis tais como: magnésio, enxofre, sódio, potássio, manganês, fósforo e titânio e, elementos traços como cromo, chumbo, zinco, vanádio, níquel e muitos outros (BATTAGIN, 2003).

Alguns tipos de resíduos não devem ser utilizados em fornos de clínquer, muitas vezes por 
restrições ambientais (legislação) e, também, pelas características do processo de fabricação de clínquer (SANTI \& CREMASCO, 2006).

Primeiramente, deve-se verificar o objetivo da utilização do resíduo, se para substituição parcial de combustível ou, como substituto parcial de matéria-prima, ou, ambos os fins.

O resíduo, para ser considerado um substituto de combustível, deve fornecer energia térmica ao processo na etapa de combustão e, quando considerado substituto parcial de matéria-prima, conter componentes majoritários como cálcio, sílica, alumínio e ferro, que são os materiais mineralizadores e/ou fundentes do processo de produção de cimento. Quando for definida uma utilização, deve-se avaliar suas propriedades físico-químicas, pois determinados contaminantes presentes no resíduo, ao serem queimados no forno, deverão ter suas quantidades limitadas (MAZZER, 2004).

A taxa máxima de alimentação do resíduo, que será queimado no forno, é estabelecida através de testes em branco, previamente efetuados. Tem, por finalidade, evitar que os limites de emissão estabelecidos pela legislação se excedam, bem como não causar impactos ambientais, não afetar as condições de segurança e saúde pública, não causar prejuízos às instalaçóes e equipamentos e, qualidade dos produtos clínquer/cimento (SANTI \& CREMASCO, 2006).

As companhias cimenteiras chegam a estar co-processando os resíduos industriais porque querem satisfazer às autoridades ambientais e, também, aos interesses das indústrias e, os materiais mais freqüentemente utilizados para esse propósito, são os resíduos carbônicos provenientes de processos industriais diferentes tais como óleos, solventes, lamas de borras de hidrocarbonetos e álcoois. Porém, não é levada em consideração a constituição química dos materiais oxidados e sais, que venham a ficar impregnados no cimento, quando este é processado a partir da queima desses resíduos, pois os mesmos contêm, geralmente, metais pesados em sua constituição. Contudo, deve ser enfatizado que as especificações para o cimento produzido utilizando, gás natural ou resíduos industriais, são as mesmas, e a sociedade não é informada dos riscos da toxidez provocada pela presença de contaminantes no cimento (SANTI \& CREMASCO, 2006).

\section{SAÚDE HUMANA VERSUS PRESENÇA DE ALGUNS METAIS ENCONTRADOS NOS RESÍDUOS}

No caso do cobre, a exposição à poeira e finos de cobre pode causar irritação nos olhos, nariz e garganta, semelhantes à gripe e associados ao sabor metálico na boca, febre e calafrios, bronco constrição e tosse. Os níveis excessivos desse metal no organismo inibem os grupos sulfidrila das enzimas, tais como glicose-6-fosfatase ${ }^{3}$ e glutation redutase ${ }^{4}$, os quais são responsáveis por proteger o organismo contra os danos provocados pelos radicais livres. A intoxicação aguda por cobre causa a erosão do epitélio gastrintestinal associado à necrose do fígado e dos rins. Além disso, o elemento cobre causa doenças ligadas à genética. Ao serem queimados resíduos com certos compostos de cobre têm-se as reaçôes, a seguir.

$$
\begin{aligned}
& \mathrm{Cu}_{2} \mathrm{~S}+2 \mathrm{O}_{2} \rightarrow 2 \mathrm{CuO}+\mathrm{SO}_{2} \\
& \mathrm{Cu}_{2} \mathrm{~S}+2 \mathrm{CuO} \rightarrow 4 \mathrm{Cu}+\mathrm{SO}_{2}
\end{aligned}
$$

Quanto ao elemento cromo, sua principal via de introdução no organismo é a respiratória e, a absorção pelas vias aéreas superiores e pulmôes pode causar câncer. Os compostos de cromo podem interagir com o DNA resultando em danos estruturais e funcionais do mesmo, com efeitos celulares, causando aberraçōes cromossômicas. A seguir, são demonstradas algumas reações de compostos de cromo quando presentes nos resíduos incinerados.

$$
\begin{aligned}
& 2 \mathrm{Na}_{2} \mathrm{CrO}_{4}+\mathrm{H}_{2} \mathrm{SO}_{4} \rightarrow \mathrm{Na}_{2} \mathrm{Cr}_{2} \mathrm{O}_{7}+\mathrm{H}_{2} \mathrm{O}+\mathrm{Na}_{2} \mathrm{SO}_{4} \\
& \mathrm{Na}_{2} \mathrm{Cr}_{2} \mathrm{O}_{7}+\mathrm{S} \rightarrow \mathrm{Cr}_{2} \mathrm{O}_{3}+\mathrm{Na}_{2} \mathrm{SO}_{4+} \text { outros } \\
& \text { compostos de cromo }
\end{aligned}
$$

O cádmio, absorvido pelos pulmões e alvéolos é encontrado em tamanho diminuto na forma de fumos. Sua maior concentração é nos rins e fígado, sendo que o pâncreas e vértebras também concentram cádmio. A placenta humana representa uma barreira parcial à exposição fetal ao cádmio. A seguir, são apresentadas reações envol-

\footnotetext{
3 Enzima para transformação de glicose 6 fosfato para glicose.

${ }^{4}$ Antioxidante celular.
} 
vidas na incineração em presença de compostos de cádmio.

$$
\begin{aligned}
& \mathrm{Cd}_{2} \mathrm{~S}+2 \mathrm{O}_{2} \rightarrow 2 \mathrm{CdO}+\mathrm{SO}_{2} \\
& \mathrm{Cd}_{2} \mathrm{~S}+2 \mathrm{CdO} \rightarrow 4 \mathrm{Cd}+\mathrm{SO}_{2}
\end{aligned}
$$

O níquel apresenta-se na atmosfera sob a forma de sulfato de níquel e seus óxidos. Estudos epidemiológicos demonstram um risco aumentado de cancro nasal e pulmonar dos trabalhadores expostos. Apresenta, também, riscos ao sistema imunológico. A seguir, são apresentadas algumas reações quando são incinerados compostos de níquel.

$$
\begin{aligned}
& \mathrm{Ni}_{2} \mathrm{~S}+2 \mathrm{O}_{2} \rightarrow 2 \mathrm{NiO}+\mathrm{SO}_{2} \\
& \mathrm{Ni}_{2} \mathrm{~S}+2 \mathrm{NiO} \rightarrow 4 \mathrm{Ni}+\mathrm{SO}_{2}
\end{aligned}
$$

\section{EXPERIMENTOS DE LIXIVIAÇÃO}

As experiências de lixiviação foram realizadas com a finalidade de se obter os teores de íons contaminantes de cobre, cromo, cádmio e níquel nas soluçōes lixiviadoras dos corpos-de-prova de cimento branco impregnados com sais dos respectivos elementos a serem analisados. (MONTEI$\mathrm{RO}, 2007$ )

Desta forma, procurou-se demonstrar a possibilidade da lixiviação de sais de alguns metais pesados no cimento produzido a partir de resíduos industriais para o meio ambiente.

\subsection{MÉTODO}

O equipamento utilizado nas experiências de lixiviação foi constituído de recipientes plásticos de $200 \mathrm{~mL}$, que continham os corposde-prova completamente imersos na solução lixiviadora. A confecção dos corpos-de-prova foi realizada com $40 \mathrm{~g}$ de cimento branco comercial, contaminados com adição de $1 \mathrm{~g}$ de um dos sais contendo o elemento contaminante (sulfato de cobre, cromato de potássio, cloreto de cádmio ou cloreto de níquel) e, adição de $10 \mathrm{~mL}$ de água desmineralizada, conforme figura 2, a seguir.

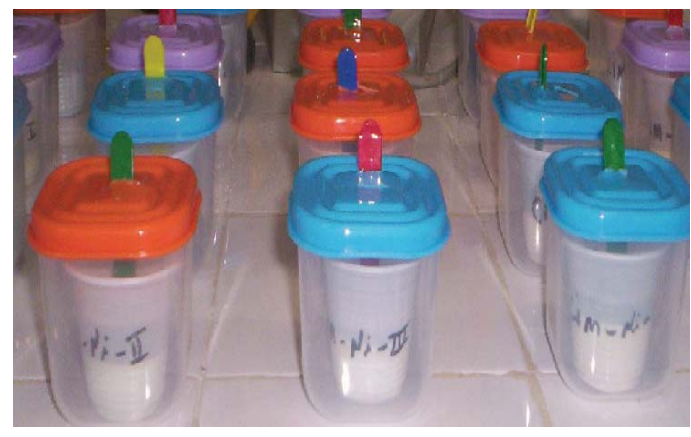

Figura 2: corpos-de-prova

Depois, a mistura resultante foi colocada em formas cônicas de poliestireno com as seguintes medidas: diâmetro maior: $5 \mathrm{~cm}$, diâmetro menor: $3 \mathrm{~cm}$ e altura de $4 \mathrm{~cm}$, totalizando uma área de $50 \mathrm{~cm}^{2}$. Foi incluída uma pequena pá de material plástico para facilitar a entrada e a retirada dos corpos-de-prova dos recipientes de lixiviação.

Os corpos-de-prova foram, então, submetidos à secagem natural por um período de dois dias e, complementação da secagem em estufa de laboratório à $120^{\circ} \mathrm{C}$ durante o período de duas horas.

A seguir, os corpos-de-prova, retirados da forma de poliestireno, sofreram operação estática de lixiviação em períodos de 14 e 28 dias nos recipientes plásticos de $200 \mathrm{~mL}$ completamente submersos em volumes de $100 \mathrm{~mL}$ de solução de hidróxido de sódio $0,1 \mathrm{mg} / \mathrm{L}$ ou ácido clorídrico 0,1 mg/L (preparado em laboratório com água desmineralizada). Foi realizado controle de $\mathrm{pH}$ da solução lixiviadora de ácido clorídrico $0,1 \mathrm{mg} / \mathrm{L}$, pois, os componentes alcalinos da matriz cimento tendem a aumentar esse valor. As correçôes de para as lixiviações com ácido clorídrico $0,1 \mathrm{mg} / \mathrm{L}$ foram realizadas com ácido clorídrico concentrado, procurando-se valores na faixa de $\mathrm{pH}$ entre 4 e 5. As lixiviações com hidróxido de sódio mantiveram valores de $\mathrm{pH}$ em torno de 12 .

Decorridos os prazos estabelecidos para a operação de lixiviação foram retiradas amostras das soluções lixiviadoras em frascos de vidro apropriados para amostragem em espectrômetro e, enviadas para análise por espectrometria de emissão com plasma de argônio indutivamente acoplado a fim de quantificar os elementos contaminantes lixiviados. A fig. 3 a seguir, apresenta o espectrômetro de emissão ótica com plasma de argônio indutivamente acoplado e, o quadro 1 abaixo, apresenta os equipamentos utilizados nos experimentos de lixiviação. 
Quadro 1: Equipamentos utilizados nos experimentos de lixiviação

\begin{tabular}{|c|c|c|c|}
\hline Equipamento & Marca & Modelo & Faixa de Trabalho \\
\hline Balança analítica & Quimis Aparelhos Científicos Ltda & Q-500L210C & 0,1mg a 210g \\
\hline Desmineralizador & Quimis Aparelhos Científicos Ltda & Q 341-25 & Q316-14 \\
\hline Estufa & Quimis Aparelhos Científicos Ltda & a 120C \\
\hline pHmetro & Quimis Aparelhos Científicos Ltda & Q4003 & pH de 0-14 \\
\hline $\begin{array}{c}\text { Espectrômetro de Emissão } \\
\text { Ótica com Plasma de } \\
\text { Argônio Indutivamente } \\
\text { Acoplado }\end{array}$ & Jobin Yvon & Ultima 2 & $\begin{array}{c}\text { Teores de } \\
\text { elementómicos de ppb } \\
\text { a ppm }\end{array}$ \\
\hline
\end{tabular}

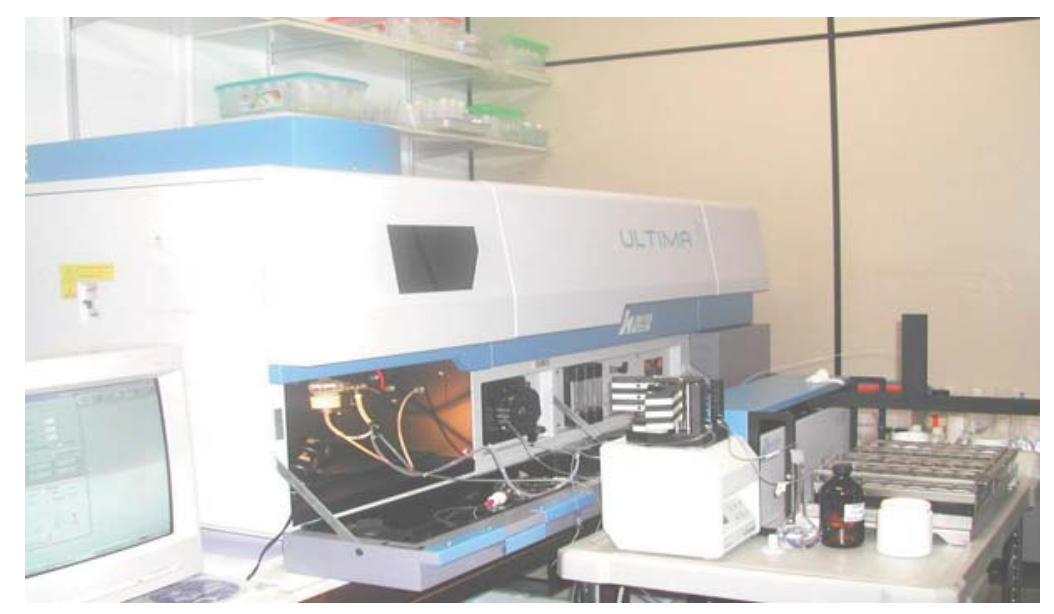

Fig.3: Espectrômetro de emissão ótica com plasma de argônio indutivamente acoplado

\subsection{ANÁLISE DOS EXPERIMENTOS}

Os experimentos são comumente realizados para demonstrar a possibilidade da lixiviação de certos contaminantes, como os compostos de metais, para o ambiente, quando esses se encontram presentes no cimento. O número de amostras analisadas foi em número de vinte para corpos-deprova impregnados por sulfato de cobre, cromato de potássio, cloreto de cádmio e cloreto de níquel, respectivamente, em tempos de cura de 28 dias (com solução $0,1 \mathrm{mg} / \mathrm{L}$ de hidróxido de sódio) e, 14 e 28 dias (com solução $0,1 \mathrm{mg} / \mathrm{L}$ de ácido clorídrico). Os tempos de cura foram determinados em função das diferenças nas condições de temperatura do forno de clínquer (cerca de $1800^{\circ} \mathrm{C}$ ) e experimentos de lixiviação ocorridos à $25^{\circ} \mathrm{C}$. O mesmo se pode dizer do $\mathrm{pH}$, pois os fornos de clínquer apresentam condições oxidantes específicas, necessitando-se para a simulação dos testes de lixiviação condições mais agressivas.

É importante ressaltar, que esse tipo de análise pode ser efetuado para qualquer elemento tóxico, como os metais, possivelmente presentes na matriz clínquer/cimento, embora o presente trabalho, queira apresentar, de forma clara, que certos tipos de controles podem ser efetuados, sem grandes complicaçōes, no que tange às normas $\mathrm{e}$ legislação pertinentes ao processo de fabricação do cimento. As tabelas 1,2,3 e 4, a seguir, apresentam os resultados para os teores de íons $\mathrm{Cu}^{2+}, \mathrm{Cr}^{6+}$, $\mathrm{Cd}^{2+} \mathrm{e} \mathrm{Ni}^{2+}$ encontrados nos testes de lixiviação. 
Tabela 1: Resultados das Análises para os Íons $\mathrm{Cu}^{2+}$

\begin{tabular}{|c|c|c|c|c|}
\hline Amostra & $\begin{array}{c}\% \text { peso inicial de } \\
\text { íons } \mathrm{Cu}^{2+}\end{array}$ & $\begin{array}{c}\text { Teor de íons } \mathrm{Cu}^{2+} \text { no } \\
\text { lixiviado }\end{array}$ & Tempo de Cura & Tipo de lixiviação \\
\hline CIM-Cu-1 & 0,83 & 0,06 & 28 & $\mathrm{NaOH} 0,1 \mathrm{mg} / \mathrm{L}$ \\
\hline CIM-Cu-2 & 0,69 & 0,02 & 14 & $\mathrm{HCl} 0,1 \mathrm{mg} / \mathrm{L}$ \\
\hline CIM-Cu-3 & 0,70 & 0,12 & 14 & $\mathrm{HCl} 0,1 \mathrm{mg} / \mathrm{L}$ \\
\hline CIM-Cu-4 & 1,02 & 0,03 & 28 & $\mathrm{HCl} 0,1 \mathrm{mg} / \mathrm{L}$ \\
\hline $\mathrm{CIM}-\mathrm{Cu}-5$ & 0,80 & 0,03 & 28 & $\mathrm{HCl} 0,1 \mathrm{mg} / \mathrm{L}$ \\
\hline
\end{tabular}

Tabela 2: Resultados das Análises para os Íons Cr6+

\begin{tabular}{|c|c|c|c|c|}
\hline Amostra & $\begin{array}{l}\text { \% em peso inicial } \\
\text { de íons } \mathrm{Cr}^{6+}\end{array}$ & $\begin{array}{c}\text { Teor de íons } \mathrm{Cr}^{6+} \text { no } \\
\text { lixiviado }\end{array}$ & $\begin{array}{l}\text { Tempo de cura } \\
\text { (dias) }\end{array}$ & Tipo de lixiviação \\
\hline CIM-Cr-1 & 0,57 & 288 & 28 & $\mathrm{NaOH} 0,1 \mathrm{mg} / \mathrm{L}$ \\
\hline CIM-Cr-2 & 0,94 & 232 & 14 & 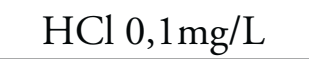 \\
\hline CIM-Cr-3 & 1,26 & 25 & 14 & 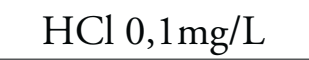 \\
\hline CIM-Cr-4 & 0,69 & 72 & 28 & 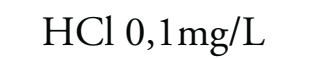 \\
\hline CIM-Cr-5 & 0,55 & 61 & 28 & $\mathrm{HCl} 0,1 \mathrm{mg} / \mathrm{L}$ \\
\hline
\end{tabular}

Tabela 3: Resultados das Análises para os Íons $\mathbf{C d}^{2+}$

\begin{tabular}{|c|c|c|c|c|}
\hline Amostra & $\begin{array}{l}\% \text { em peso inicial } \\
\text { de íons } \mathrm{Cd}^{2+}\end{array}$ & $\begin{array}{l}\text { Teor de íons } \mathrm{Cd}^{2+} \text { no } \\
\text { lixiviado }(\mathrm{ppm})\end{array}$ & $\begin{array}{l}\text { Tempo de cura } \\
\text { (dias) }\end{array}$ & Tipo de lixiviação \\
\hline CIM-Cd-1 & 1,41 & 0,001 & 28 & $\mathrm{NaOH} 0,1 \mathrm{mg} / \mathrm{L}$ \\
\hline CIM-Cd-2 & 1,06 & 0,002 & 14 & $\mathrm{HCl} 0,1 \mathrm{mg} / \mathrm{L}$ \\
\hline CIM-Cd-3 & 1,14 & 0,004 & 14 & $\mathrm{HCl} 0,1 \mathrm{mg} / \mathrm{L}$ \\
\hline CIM-Cd-4 & 1,16 & 0,001 & 28 & $\mathrm{HCl} 0,1 \mathrm{mg} / \mathrm{L}$ \\
\hline CIM-Cd-5 & 1,07 & 0,002 & 28 & $\mathrm{HCl} 0,1 \mathrm{mg} / \mathrm{L}$ \\
\hline
\end{tabular}

Tabela 4: Resultados das Análises para os Íons $\mathrm{Ni}^{2+}$

\begin{tabular}{|c|c|c|c|c|}
\hline Amostra & $\begin{array}{l}\% \text { em peso inicial } \\
\text { de íons } \mathrm{Ni}^{2+}\end{array}$ & $\begin{array}{c}\text { Teor de íons } \mathrm{Ni}^{2+} \text { no } \\
\text { lixiviado }\end{array}$ & $\begin{array}{l}\text { Tempo de cura } \\
\text { (dias) }\end{array}$ & Tipo de lixiviação \\
\hline CIM-Ni-1 & 0,78 & 0,002 & 28 & $\mathrm{NaOH} 0,1 \mathrm{mg} / \mathrm{L}$ \\
\hline CIM-Ni-2 & 0,62 & 0,006 & 14 & $\mathrm{HCl} 0,1 \mathrm{mg} / \mathrm{L}$ \\
\hline CIM-Ni-3 & 1,01 & 0,022 & 14 & $\mathrm{HCl} 0,1 \mathrm{mg} / \mathrm{L}$ \\
\hline CIM-Ni-4 & 0,70 & 0,004 & 28 & $\mathrm{HCl} 0,1 \mathrm{mg} / \mathrm{L}$ \\
\hline CIM-Ni-5 & 0,54 & 0,005 & 28 & $\mathrm{HCl} 0,1 \mathrm{mg} / \mathrm{L}$ \\
\hline
\end{tabular}




\section{CONCLUSŌES RECOMENDAÇŌES}

- os ensaios laboratoriais utilizando lixiviação em corpos-de-prova com cimento branco contaminados com sais de metais pesados mostraram que é possível a contaminação ambiental, a partir de cimento produzido, incinerando-se resíduos industriais em seus fornos;

- o fato de não se ter controle quantitativo do que possa vir estar impregnado na matriz cimento, ou seja, se menores ou maiores teores de determinado contaminante e, que este possa, independente de sua concentração, vir a ser lixiviado para o meio ambiente, é fato que deve ser computado e passível de investigação pelas autoridades competentes do assunto;

- a maior parte dos trabalhadores da indústria do cimento e entornos, não questionam a queima desses ou daqueles resíduos nos fornos, apenas convivem com essa realidade e, a grande preocupação dos "empresários" é o aproveitamento de forma sustentável desse resíduo ambiental incômodo e causador de problemas junto à legislação ambiental que os controla;

- no que diz respeito aos métodos de análises químicas para quantificação específica de contaminantes, que podem estar presentes no cimento produzido a partir da incineração de resíduos, são escassos e pouco desenvolvidos;

- os fornos de cimenteiras não reúnem condições necessárias para regular o processo de incineração de resíduos industriais, nem mecanismos eficazes de controle da contaminação que se produz durante o referido processo, pois, não existem informações de que sejam realizadas adaptaçóes nos fornos ao se queimar resíduos em lugar de combustíveis convencionais;

- torna-se negligente e irresponsável a venda de resíduos industriais com contaminantes não declarados para a sua incineração em qualquer forno industrial;

- diante dos perigos referentes às contaminações do cimento produzido a partir do uso de resíduos industriais, deve-se evitar o máximo a sua utilização sem qualquer controle adicional e, caso não seja possível a prática responsável, é de boa conduta, utilizar somente combustíveis "limpos";

- essas observações não são pertinentes somente aos problemas que envolvem a fabricação de cimento a partir da queima de resíduos in- dustriais, mas, para toda e qualquer agressão ambiental que decorra de processos industriais que não se importem com as rotas tecnológicas utilizadas.

\section{BIBLIOGRAFIA}

BRAGA,T.M., Risco e conflito ambiental sob o signo da (mono) indústria: um estudo sobre políticas ambientais na bacia do rio Piracicaba, Minas Gerais. In: População e meio ambiente: debates e desafios/ Haroldo Torres e Heloisa Costa (organizadores) - São Paulo: Editora SENAC, São Paulo, 2000 .

BATTAGIN, Arnaldo Forti, O Mundo do Cimento, 2003 in: www.cimento.org .Consultado em fev/2007.

CAVALCANTI, J.E., A década de 90 é dos resíduos sólidos. Revista Saneamento Ambiental, no 54, p.16-24, nov/dez/1998.

SANTI, A.M.M. \& SEVÁ, Fo.O.S., Resíduos renováveis e perigosos como combustíveis industriais. Estudo sobre a difícil sustentação ambiental da fabricação de cimento no Brasil, anos 1990, VIII Congresso Brasileiro de Energia, RJ, dez/1999.

LEMARCHAND, Daniel, Cement kiln incineration associated to pretreatment, a viable waste management solution. In: Congresso Brasileiro de Cimento, 5, SP, nov/1999, Anais São Paulo, 1999.

SANTI, A.M.M., CREMASCO, M. S., Combustíveis e riscos tecnológicos ambientais na fabricação do cimento: avaliação contextualizada no município de Barroso, Minas Gerais, III Encontro da ANPPAS, Brasília, maio/2006.

MAZZER, C., CAVALCANTI, O., A., Introdução à gestão ambiental de resíduos, Infarma, v.16,no11-12, 2004.

MONTEIRO, L.P.C., Impacto Ambiental Associado à Queima de Combustíveis Alternativos em Fornos de Clínquer: Visão sob o Prisma da Educação Ambiental. Tese de Doutorado, out/2007, $\mathrm{UFF}-\mathrm{RJ}$. 
LIN,X.D.,POON,C.S.,SUN,H.,LO,I.M.C.,KIR K,D.W. Heavy metals speciation and leaching behaviors in cement based solidified/stabilized waste materials. Journal of Hazardous Materials, v.82, n.3, apr/2001, p.215-230.
EPA-Environmental Protection Agency, Test methods for evaluation solid waste, toxicity characteristics leading procedure (TCLP): Method 1311, Revision 0, 35 p. Physical /chemical methods. SW-846, 1992. 